\title{
Opioid Use among Patients with Early Inflammatory Arthritides Compared to the General Population
}

\author{
Paula Muilu (D), Vappu Rantalaiho (1D), Hannu Kautiainen (1D), Lauri Juhani Virta (1D, \\ and Kari Puolakka ${ }^{\mathbb{D}}$
}

\begin{abstract}
Objective. To assess to what extent the worldwide opioid epidemic affects Finnish patients with early inflammatory arthritis (IA).

Methods. From the nationwide register maintained by the Social Insurance Institution of Finland, we collected all incident adult patients with newly onset seropositive and seronegative rheumatoid arthritis (RA+ and RA-) and undifferentiated arthritis (UA) between 2010 and 2014. For each case, 3 general population (GP) controls were matched according to age, sex, and place of residence. Drug purchases between 2009 and 2015 were evaluated 1 year before and after the index date (date of IA diagnosis), further dividing this time into 3 -month periods.

Results. A total of 12,115 patients (66\% women) were identified. At least 1 opioid purchase was done by $23-27 \%$ of the patients 1 year before and $15-20 \%$ one year after the index date. Relative risk (RR) of opioid purchases compared to GP was highest during the last 3-month time period before the index date [RR 2.81 (95\% CI 2.55-3.09), 3.06 (2.68-3.49), and 4.04 (3.51-4.65) for RA+, RA-, and UA, respectively] but decreased after the index date [RR 1.38 (1.23-1.58), 1.91 (1.63-2.24), and 2.51 (2.15-2.93)]. Up to $4 \%$ of the patients were longterm users both before and after the diagnosis.

Conclusion. During 2009-15 in Finland, opioid use peaked just before the diagnosis of IA but decreased rapidly after that, suggesting effective disease control, especially in seropositive RA. Further, opioids were used to treat arthritis pain of patients with incident RA and UA less often than previously reported from other countries. (First Release April 1 2020; J Rheumatol 2020;47:1285-92; doi:10.3899/jrheum.190355)
\end{abstract}

Key Indexing Terms:

RHEUMATOID ARTHRITIS

OPIOID ANALGESICS

Drug therapy outcomes in inflammatory arthritis (IA) have improved during the past 2 decades; however, arthritis pain

From the Department of Medicine, Tampere University Hospital; Centre for Rheumatic Diseases, Tampere University Hospital; Faculty on Medicine and Health Technology, Tampere University, Tampere; Department of General Practice and Primary Health Care, University of Helsinki and Helsinki University Hospital; Primary Health Care Unit, Kuopio University Hospital, and Folkhälsan Research Centre, Helsinki; Unit of Primary Health Care, Turku University Hospital; Research Department, Social Insurance Institution of Finland, Turku; Department of Medicine, South Karelia Central Hospital, Lappeenranta, Finland.

This study was funded by Competitive State Research Financing of the Expert Responsibility Area of Tampere University Hospital, the Finnish Rheumatology Research Foundation, Tampereen Reumayhdistys, and by the Finnish Cultural Foundation.

P. Muilu, MD, Medical Specialist in Internal Medicine in the Department of Internal Medicine, Centre for Rheumatic Diseases, Tampere University Hospital; V. Rantalaiho, MD, PhD, Docent, Specialist in Rheumatology in the Department of Internal Medicine, Centre for Rheumatic Diseases, Tampere University Hospital and Faculty on Medicine and Health Technology, Tampere University; H. Kautiainen, Biostatistician, Primary Health Care Unit, Kuopio University Hospital, and Folkhälsan Research Centre; L.J. Virta, MD, PhD, Docent, Research Department, Social Insurance Institution of Finland; K. Puolakka, MD, PhD, Docent, Specialist in Rheumatology, Chief of Division, Department of Internal Medicine, Centre for Rheumatic Diseases, South Karelia Central Hospital.

Address correspondence to Dr. P. Muilu, Teiskontie 35, 33520 Tampere,

Finland.E-mail: paula.muilu@gmail.com, paula.muilu@pshp.fi

Accepted for publication September 24, 2019.
UNDIFFERENTIATED ARTHRITIS

PAIN

management remains a challenge ${ }^{1,2}$. Arthritis pain is often multifactorial, including inflammation and irreversible joint degeneration, and patients with IA may also have abnormalities in central pain processing or several comorbidities that induce pain ${ }^{3,4}$. Patients with rheumatoid arthritis (RA) consider pain relief as the most important area of health improvement and it is also their most common motive for seeking medical consultation ${ }^{5,6}$.

Nonsteroidal antiinflammatory drugs (NSAID) are considered first-line analgesics in $\mathrm{IA}^{6,7}$, but increasing evidence of gastrointestinal, cardiovascular, and kidney-related side effects have reduced their use ${ }^{8,9}$. Pain-relieving effects of NSAID may improve when used in combination with paracetamol (acetaminophen); however, adverse effects rise simultaneously ${ }^{10}$. The followup periods in studies investigating the effectiveness of opioids in arthritis or musculoskeletal-related pain are often short in duration ${ }^{1,11,12,13,14}$. These studies usually emphasize the risks of adverse effects and do not support the benefits of longterm opioid treatment or the use of strong opioids $s^{1,11,12,13,14}$. In addition to well-known harm outcomes such as addiction among patients with RA, exposure to opioids has been shown to increase the risk of serious infections linked to hospitalizations ${ }^{15}$ or nonvertebral fractures mostly related to falls ${ }^{16}$, and

Personal non-commercial use only. The Journal of Rheumatology Copyright @ 2020 . All rights reserved. 
cause delay in the initiation of disease-modifying antirheumatic drugs (DMARD) for the treatment of $\mathrm{RA}^{17}$. Current recommendations thus state that opioids should be used only after careful consideration in $\mathrm{IA}^{1,7}$.

The rather liberal management of chronic nonmalignant pain has partially contributed to the current worldwide opioid epidemic. Most of the literature on the current opioid epidemic, however, comes from the United States, and to our knowledge, there are few epidemiological reports on opioid use from the Nordic countries ${ }^{18,19,20}$ and none in the setting of inflammatory rheumatic diseases. In this analysis, we wanted to assess what happens in the setting of early IA, where the pain in an undiagnosed disease is a true problem, but the need for pain medication should decline quickly when accurate antirheumatic treatment is given.

\section{MATERIALS AND METHODS}

The Finnish social security system is organized by the Social Insurance Institution (SII) and provides all permanent residents in Finland a variety of benefits. The costs of most medicines prescribed by a doctor for the treatment of a disease are partially reimbursed by SII, either at a basic, lower special, or higher special rate, depending on the disease and its severity. Patients with chronic IA can be granted a special reimbursement (SR; reimbursement of $65-72 \%$ of the drug price) for antirheumatic drugs after filling out a medical certificate to SII. This certificate must describe the diagnostic procedures and prescribed medication and be written in a rheumatology clinic. SII maintains a register on these SR, including patients' age, sex, International Classification of Diseases, 10th revision (ICD-10) code of the disease, and date of entitlement.

From these national registry data we collected all incident adult patients (aged $\geq 18 \mathrm{yrs}$ ) granted the first SR for medications of either seropositive RA, seronegative RA, or UA from January 1, 2010, to December 31, 2014. The patients were identified with an ICD-10 code: seropositive RA (M05), seronegative RA (M06), and UA (M13). The dates (month and year) when the decision regarding the special refund for antirheumatic drugs took effect was used as a proxy indicator of the date of IA diagnosis, that is, the index date in our study.

For each incident case, 3 eligible controls were randomly selected from the Population Register Centre and were individually matched to the cases by age, sex, and place of residence. Also, adjustments by education levels (basic, middle, lower high, and upper high level) were performed. Those persons among controls that had been granted SR for any IA before year 2010 were excluded.

Drug purchases of analgesics between 2009 and 2015 were obtained from the Drug Purchase Register. This register, also maintained by SII (since 1994), covers all drug purchases prescribed by physicians (a prescription is mandatory for opioids) and reimbursed by National Sickness Insurance Scheme in Finland. These data include information on drug class, quantity, and date of dispensing. Drugs are categorized according to the Anatomical Therapeutic Chemical Classification System, developed by the World Health Organization for drug consumption statistics. Our main focus was on opioids [N02A; mild opioids (codeine combination products and tramadol), moderate opioids (buprenorphine), and strong opioids (morphine, hydromorphine, oxycodone, and fentanyl)], but we also analyzed the purchases of NSAID (M01A) and paracetamol (N02BE01). We restricted our analysis to drug purchases starting from 2009 because of inconsistent reimbursement of codeine combination products (the most frequently used opioid in Finland) before that. Drug purchases were evaluated 1 year before and after the index date, further dividing the observation time into 3-month time periods. The drug reimbursement regulations (of the National Sickness Insurance Scheme) restrict the refunded drug supply period to a maximum of 3 months per purchase. Longterm opioid use was defined as at least 1 opioid purchase in 3 or 4 quarters per year, and in that analysis all opioids from mild to strong were included, together, 1 year before and 1 year after the index date.

Statistical methods. Statistical comparisons between the cases and controls were made using the chi-square test or generalized linear models with binomial family and log link. Longitudinal measures were analyzed using generalizing estimating equations models with the unstructured correlation structure with appropriate distribution and link function. Stata 15.1 (StataCorp LP) statistical package was used for the analysis.

Ethical considerations. Permission to use databases was obtained from the SII. In accordance with Finnish legislation, approval by an ethics committee and informed consent are not required for register-based studies done without contacting the study subjects.

\section{RESULTS}

A total of 12,115 adult patients with either seropositive RA, seronegative RA, or UA were identified. Of these, 6186 patients (66\% women) had seropositive RA, 2970 patients (67\% women) had seronegative RA, and 2959 patients (67\% women) had UA. The mean ages (SD) at diagnosis were 58 (15), 57 (17), and 49 (17) years for seropositive RA, seronegative RA, and UA, respectively. One percent of the controls and $0.9 \%$ of the patients died during the first year after the index date. In these cases, patients were followed until their death.

The proportion of opioid, NSAID, and paracetamol purchasers among patients with RA and UA and their controls during the year before and after the index date, further dividing the observation time into quarters, is shown in Figure 1. The opioid purchases peak during the last 3-month period before the index date in all diagnosis groups. The drop in opioid purchases among patients took place rapidly after the index date when antirheumatic medication was presumably initiated; a similar drop did not exist in the control groups. After this drop, the frequency of opioid use leveled off and no significant decrease was further seen in any diagnosis groups during the observation time. Still, 1 year after the index date, patients with IA purchased more opioids than did controls, this difference being most evident in UA. The use of NSAID and paracetamol was more common both in IA groups and in the general population (GP) than the use of opioids, but also their purchases peaked among IA but not among controls in a similar way as seen in opioids (Figure 1).

Figure 2 shows the risk ratio (RR) of opioid purchases among RA and UA patients 1 year before and after the index date by quarters compared to their controls. In RA, the RR gradually increased before the index date and was highest during the last quarter before the index date (RR $2.81,95 \%$ CI 2.55-3.09 for seropositive RA and 3.06, 95\% CI 2.68-3.49 for seronegative RA), but decreased rapidly after the index date, especially in seropositive RA (RR 1.38, 95\% CI 1.23-1.58) but also in seronegative RA $(1.91,95 \%$ CI 1.63-2.24). Patients with UA were up to 4 times more likely (RR 4.04, 95\% CI 3.51-4.65) opioid purchasers than

Personal non-commercial use only. The Journal of Rheumatology Copyright $(\subset) 2020$. All rights reserved. 

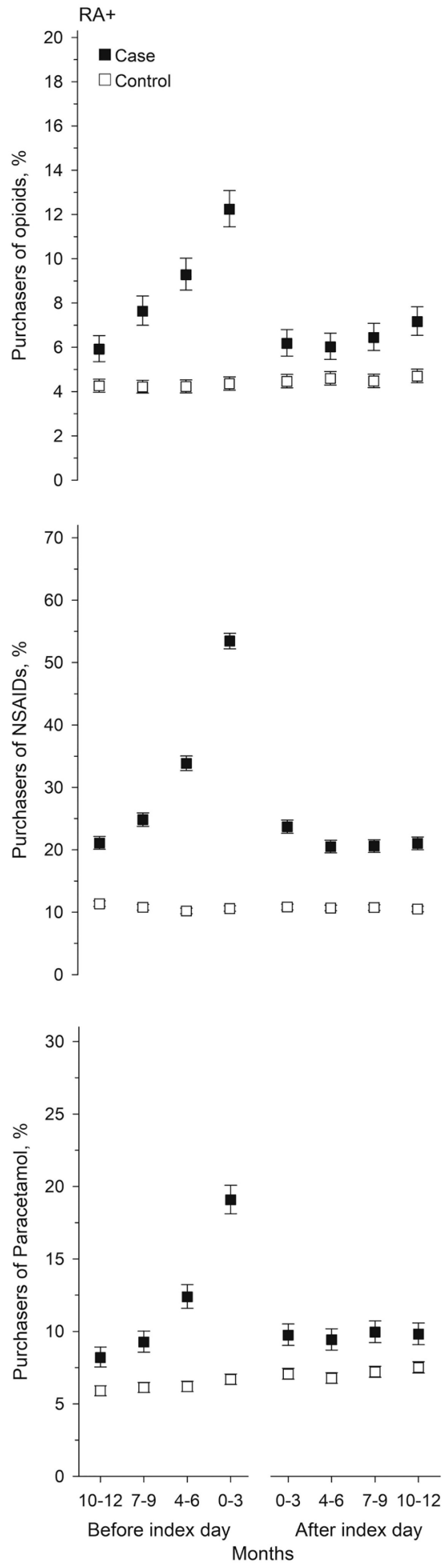

RA-

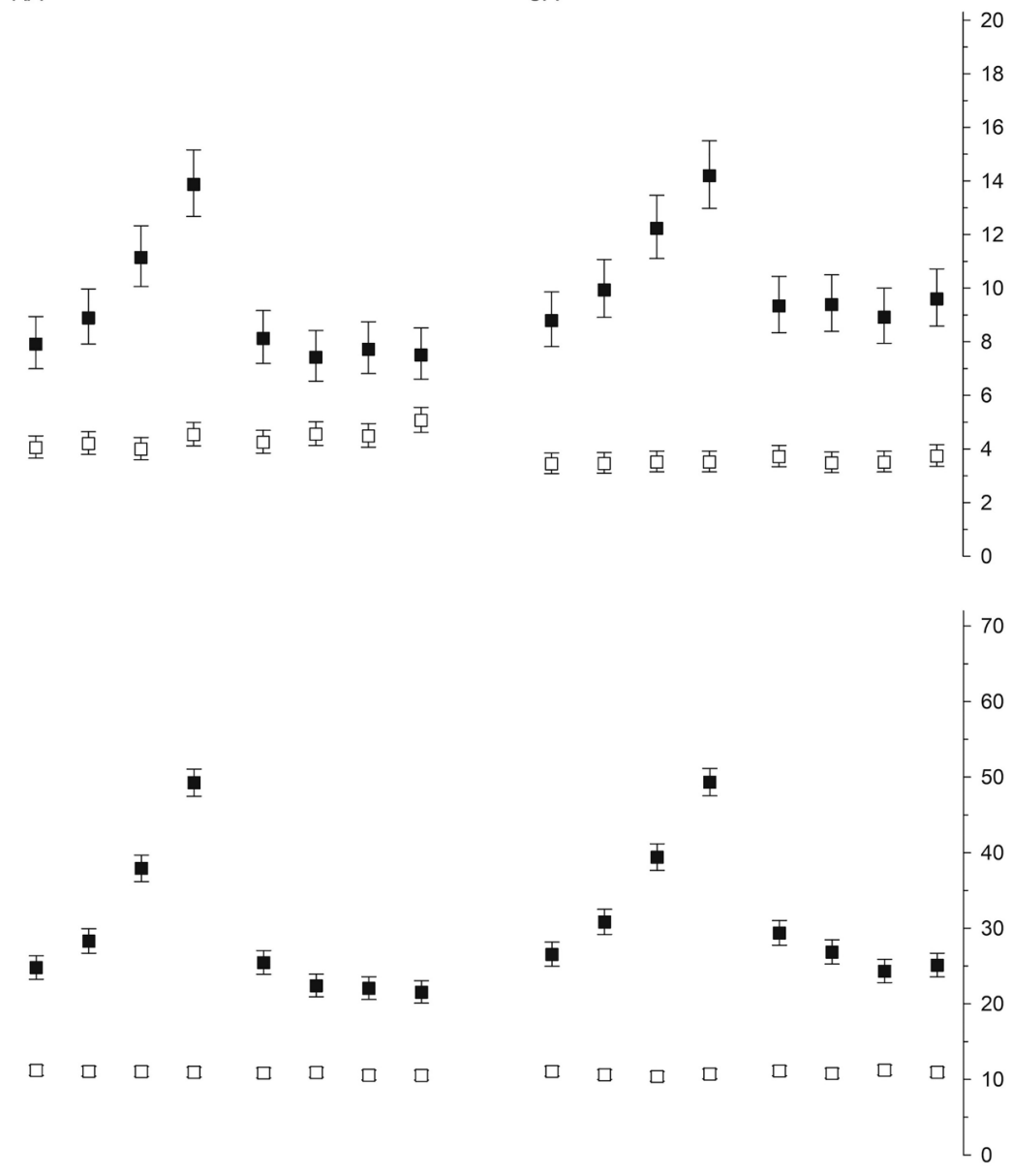

UA
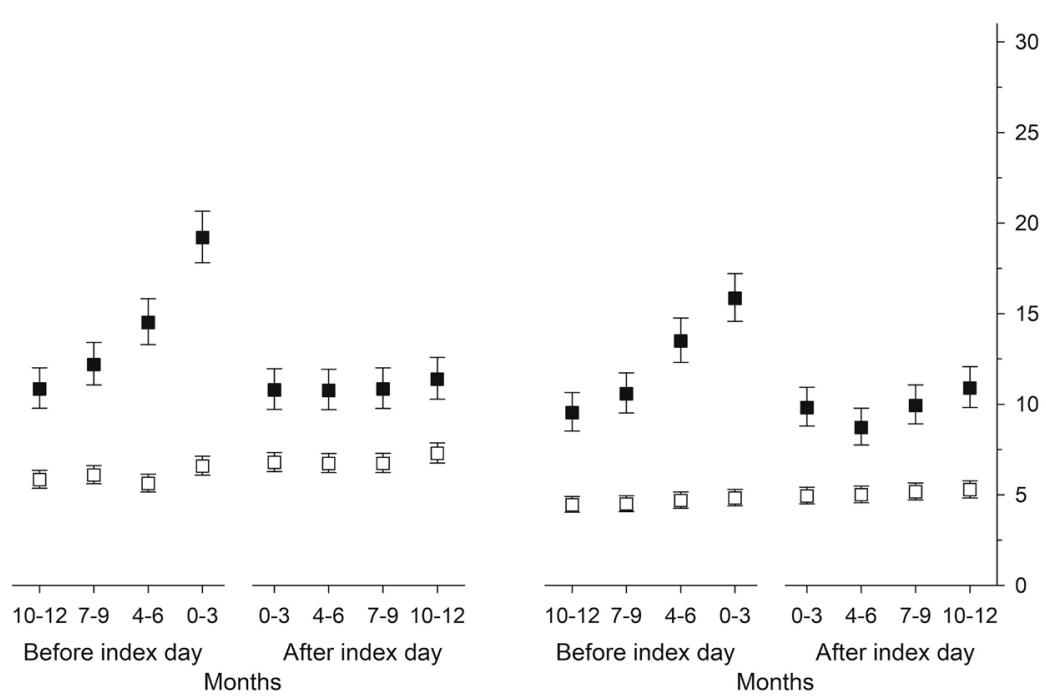

Figure 1. The proportion (\%) of opioid, NSAID, and paracetamol purchasers among patients with seropositive RA (RA+), seronegative RA (RA-), and UA and their controls 1 year before and after the index date (the date when special reimbursement for antirheumatic drugs became effective). The index date is shown in the middle of the X-axis, and the 2-year observation time has been divided into 3-month periods. NSAID: nonsteroidal antiinflammatory drug; RA: rheumatoid arthritis; UA: undifferentiated arthritis.

$$
\text { Personal non-commercial use only. The Journal of Rheumatology Copyright } @ \text { } \odot 2020 \text {. All rights reserved. }
$$




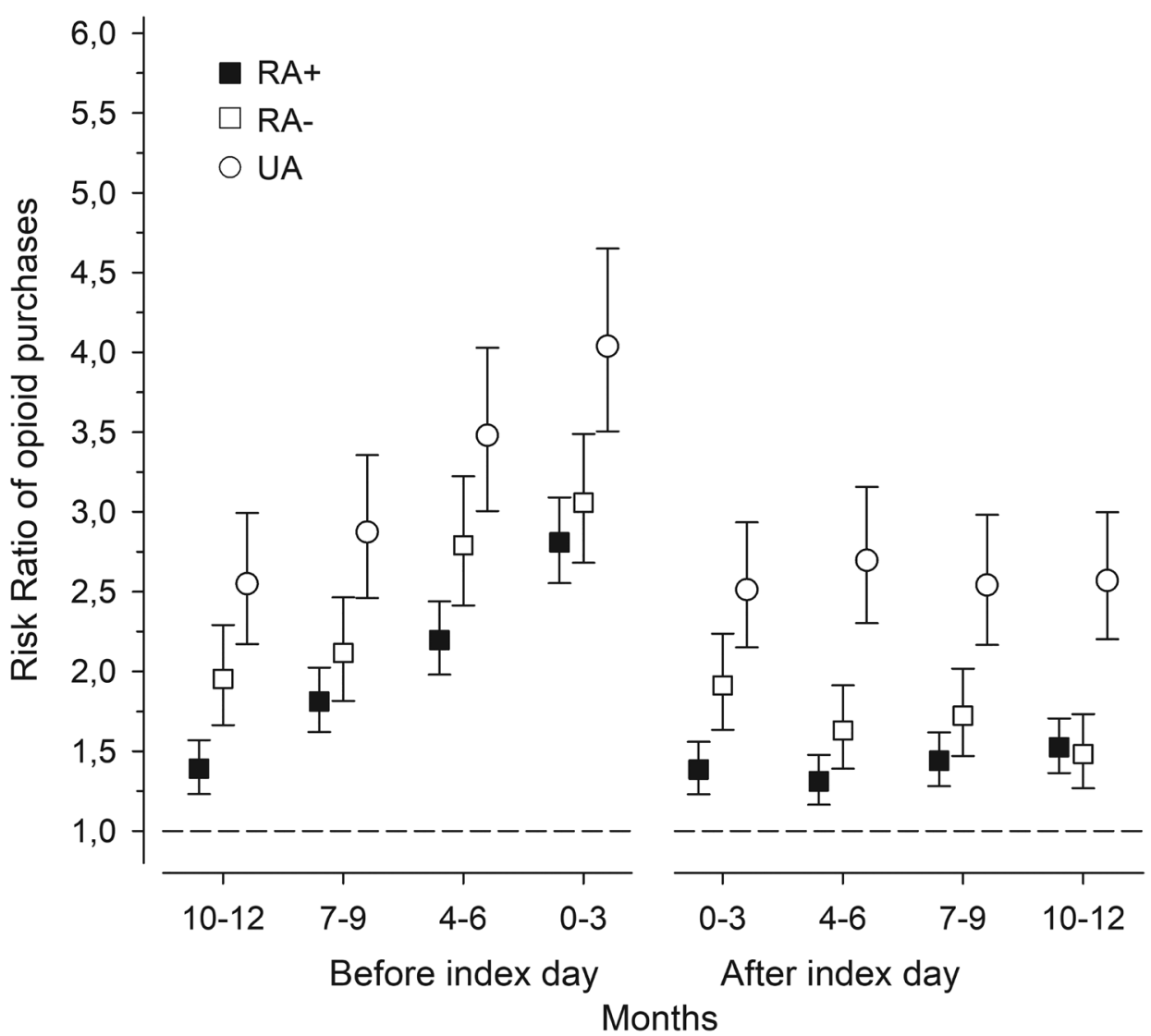

Figure 2. The risk ratio of opioid purchases among patients with seropositive RA (RA+), seronegative RA (RA-), and UA compared to their controls 1 year before and after the index date (the date when special reimbursement for antirheumatic drugs became effective). The index date is shown in the middle of the X-axis, and the observation time has been divided into 3-month periods. RA: rheumatoid arthritis; UA: undifferentiated arthritis.

their controls during the last quarter before the index date, and still a 2.5-fold difference (RR 2.51, 95\% CI 2.15-2.93) remained during the whole first year after the index date.

Table 1 shows the proportions of any opioid purchasers as well as longterm users (as defined in the Methods section) during the whole year before and after the index date. Longterm opioid use was more common among patients with IA both before and after the index date compared to their controls. After the index date, patients with UA seem more likely (RR 3.5) to be longterm opioid users than do patients with RA (RR 1.3 and 1.9 for seropositive and seronegative RA, respectively), although they were substantially younger at diagnosis than patients with RA. Instead, in the control population, longterm opioid use increased with rising age. Based on the differences in the proportions of opioid purchasers among cases and controls, about $1-4 \%$ of patients with IA seem to use opioids over the long term for their arthritis pain. The relative risk did not differ significantly between the years before or after the index date in any of the 3 diagnosis groups, indicating that longterm opioid use may stabilize early in the disease course. The RR were slightly lower across the board when adjusted by the education level.
The majority of purchased opioids were mild opioids in all diagnosis groups (Figure 3). Mild opioids were purchased most frequently by patients with UA; of these, $32.4 \%$ had at least 1 purchase during the 2-year observation time. Patients with IA purchased more opioids of any type (mild, moderate, or strong) compared to controls, and the difference reached statistical significance in all groups with the exception of seropositive RA, where arthritis pain seems not to be treated by strong opioids (Figure 3 ).

The only group in which opioid purchases differed between men and women was seropositive RA during the year before the index date, where $25.3 \%(95 \% \mathrm{CI}$ 23.4-27.2) of men purchased opioids compared to $21.4 \%$ (95\% CI 20.2-22.7) of women ( $\mathrm{p}<0.001)$. No sex differences were seen in the control groups.

\section{DISCUSSION}

Our study shows that opioids were used at least once by $23 \%$ of seropositive RA, $25 \%$ of seronegative RA, and $27 \%$ of patients with UA during the year preceding the diagnosis, and by $15 \%$ of seropositive RA, $16 \%$ of seronegative RA, and $20 \%$ of UA patients during the year following the diagnosis, whereas on average $11 \%$ of the controls of patients

Personal non-commercial use only. The Journal of Rheumatology Copyright (C) 2020. All rights reserved. 
Table 1. The proportion of individuals who purchased opioids at least once or were longterm opioid users, among patients with seropositive rheumatoid arthritis (RA+), seronegative RA (RA-), and undifferentiated arthritis (UA) and their controls 1 year before and after the index date (the date when special reimbursement for antirheumatic drugs became effective).

\begin{tabular}{|c|c|c|c|c|}
\hline Variables & Case, $\%(95 \%$ CI $)$ & Control, \% (95\% CI) & $\begin{array}{c}\mathrm{RR}(95 \% \mathrm{CI}) \\
\text { Crude }\end{array}$ & $\begin{array}{c}\text { RR }(95 \% \text { CI }) \\
\text { Adjusted }\end{array}$ \\
\hline \multicolumn{5}{|c|}{ Any opioid purchase } \\
\hline \multicolumn{5}{|l|}{$\mathrm{RA}+$} \\
\hline Before & $22.7(21.7-23.8)$ & $9.8(9.4-10.2)$ & $2.32(2.18-2.47)$ & $2.27(2.13-2.42)$ \\
\hline After & $15.4(14.5-16.3)$ & $10.9(10.5-11.4)$ & $1.41(1.31-1.51)$ & $1.38(1.28-1.48)$ \\
\hline \multicolumn{5}{|l|}{ RA- } \\
\hline \multicolumn{5}{|l|}{ UA } \\
\hline Before & $26.5(24.9-28.1)$ & $8.9(8.3-9.5)$ & $2.97(2.72-3.25)$ & $2.94(2.68-3.21)$ \\
\hline After & $19.7(18.3-21.2)$ & $9.5(8.9-10.2)$ & $2.07(1.88-2.28)$ & $2.04(1.85-2.24)$ \\
\hline \multicolumn{5}{|c|}{ Longterm opioid users } \\
\hline \multicolumn{5}{|l|}{ RA+ } \\
\hline Before & $3.2(2.8-3.7)$ & $2.2(2.0-2.4)$ & $1.46(1.24-1.73)$ & $1.40(1.19-1.66)$ \\
\hline \multicolumn{5}{|l|}{ UA } \\
\hline Before & $5.4(4.6-6.3)$ & $1.5(1.2-1.7)$ & $3.67(2.92-4.61)$ & $3.57(2.85-4.49)$ \\
\hline After & $5.5(4.7-6.4)$ & $1.6(1.3-1.9)$ & $3.46(2.77-4.33)$ & $3.37(2.70-4.21)$ \\
\hline
\end{tabular}

Risk ratios (RR) for any opioid purchase and longterm opioid use are given. The controls were individually matched to the cases regarding age, sex, and place of residence. The adjustment by the education level is also shown.

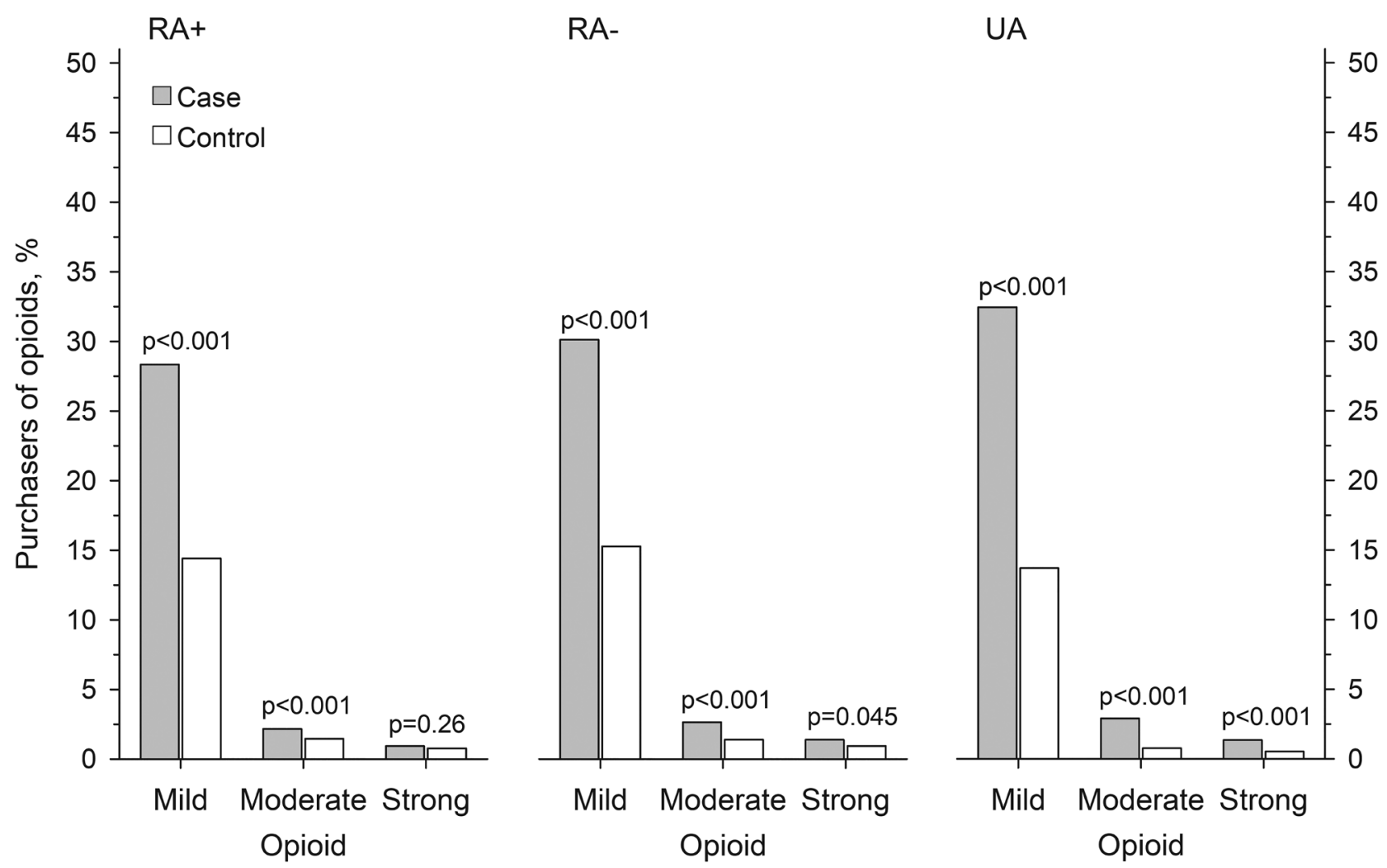

Figure 3. The distribution of opioid purchasers by the opioid type (mild, moderate, strong) among patients with seropositive RA (RA+), seronegative RA (RA-), and UA during the 2-year observation period. For each diagnosis group, the results are compared to controls adjusted for age, sex, and place of residence. Patients having combined use of different opioid types are shown in all groups in question. RA: rheumatoid arthritis; UA: undifferentiated arthritis. 
with RA and $9 \%$ of the controls of patients with UA had at least 1 opioid purchase during the 2-year observation period. Opioid purchases reached the highest levels just before the index date in all 3 diagnosis groups. Longterm opioid use was also more common among the patients; during the first year after diagnosis, patients with seropositive RA were 1.3 times, patients with seronegative RA 1.9 times, and patients with UA 3.5 times more likely longterm opioid users than their controls from the GP. In our trial, the vast majority of opioids purchased were mild in all groups.

In our study, opioid use especially among patients with seropositive RA decreased rapidly once the diagnosis had been set, presumably indicating initiation of antirheumatic drugs and effective disease control with DMARD. The same progress was seen in seronegative RA and somewhat less sharply in UA. In all diagnoses the purchases of NSAID and paracetamol showed similar trends, even though the percentages of patients purchasing these medications were markedly higher.

Thus the decrease in pain medication purchases in UA was less marked after the diagnosis of the inflammatory disease than in RA. Also, according to current results, patients with UA had a higher risk of using opioids throughout the whole year before and after the diagnosis than did patients with RA. The difference was even more marked when taking into account that the patients with UA were about 8-9 years younger at diagnosis than the patients with RA, while in the GP, opioid use became more common with rising age. We can only speculate on the possible reasons. Controlling arthritis pain may be more challenging in UA than in RA, possibly owing to somewhat less aggressive initial antirheumatic medication (unpublished data). Patients with seronegative RA have been shown to experience higher disease activity and delayed remission, partly because of changed diagnostics and the requirement for more joint involvement at diagnosis ${ }^{21}$, which may partly explain the differences in opioid use between the 2 RA serotypes. Further, patients with seronegative RA and UA may actually have another condition, such as crystal arthropathy, osteoarthrosis, or hemochromatosis that may not respond to traditional DMARD, which explains why those groups had more need of pain medication than do the seropositives.

We also demonstrated that longterm opioid use after the index date was most common among patients with UA (6\%) and least common among patients with seropositive RA (3\%). Among the controls of patients with UA and RA, longterm opioid use was around $2 \%$ during the study period. No statistically significant differences were seen in the frequencies of longterm opioid use between the years before and after the index date in any of the 3 diagnosis groups, suggesting that those who end up being longterm users will continue to use opioids chronically even after initiation of DMARD treatment. This is an important finding and highlights the risk for opioid addiction. Similarly, patients with osteoarthritis who undergo joint replacement surgery, and thus should be pain-free after some time postoperatively, are at risk of prolonged opioid use at least 12 months after surgery if they have used opioids preoperatively ${ }^{22}$. Thus, contraindication for NSAID, painful comorbidities, and wrong diagnoses may lead to harmful longterm use of opioids.

Only a few studies have reported opioid use frequency in IA and these studies have focused specifically on RA $^{17,23,24,25,26}$. Most of these studies are from the United States, where opioid consumption has reached epidemic levels during the past decades. Studies performed in a single medical center there compared RA (diagnosed at least 10 yrs earlier) with non-RA and showed that opioid use was higher in the RA group; in 2014, the rate of any opioid use was $40 \%$ and chronic use (defined as prescriptions for $\geq 60$ days within a 6-month period or those individuals using extended-use formulations) was $12 \%{ }^{23}$. A study based on data from the Corrona registry explored the frequency of self-reported chronic opioid use among 33,739 patients with RA, and found that chronic use rate, defined as any opioid use reported during $\geq 2$ clinic visits that occurred once every 3 months, was $7 \%$ in 2002 and $17 \%$ in $2015^{24}$. Another study from the United States based on Medicare data between 2006 and 2014 showed that the proportion of regular opioid users, defined as those with $\geq 3$ filled prescriptions or $\geq 1$ opioid prescription filled for at least a 90-day supply for every 12 -month period, has slightly declined after 2010, although was still $41 \%$ by $2014^{25}$. Even higher numbers were shown in a US study based on a large claims database between 2006 and 2014; this study identified 63,101 newly diagnosed patients with RA and reported that the proportions of any opioid users and chronic opioid users (those who received $\geq 180$ days' supply of opioid medication during an average of $3.5 \pm 2.1 \mathrm{yrs}$ of followup) were $72 \%$ and $25 \%$ among the patients who received DMARD therapy versus $57 \%$ and $19 \%$ among those who did not ${ }^{17}$. According to our unpublished results, more than $97 \%$ of the patients with RA and UA purchased DMARD during the first year after the diagnosis. In a German study including a total of 3140 RA patients, any opioid use rate ranged from $6 \%$ to $33 \%$ in the year 2015 depending on the reported pain levels; these proportions were closer to numbers found in our study ${ }^{26}$. Recently, a single study from the United States showed that in addition to patients with RA, opioid use was also common among patients with ankylosing spondylitis (AS); about one-quarter of the AS patients in the commercial claims database group and more than three-quarters of the patients in the Medicaid population were reported to have chronic opioid use (defined as $\geq 90$ days of drug supply) ${ }^{27}$.

Socioeconomic status has been shown to have an effect on opioid use $\mathrm{e}^{28,29}$, but when we adjusted our results according to the education level, the effect was low.

The majority of opioids purchased by patients with RA Personal non-commercial use only. The Journal of Rheumatology Copyright @ 2020 . All rights reserved. 
or UA in our study were mild opioids. Even though we do not face a similar problem with strong opioids compared to some Western countries, all opioids, even weak ones, are potentially addictive, and may be used, for example, in combination with alcohol or other drugs, and therefore should only be prescribed for valid indications. In Finland, the consumption rate of strong opioids has shown a subtle rising trend during recent years; still, the definite majority of prescribed opioids in Finland are mild opioids, especially codeine combination products ${ }^{30}$. In 2009 in Finland, the total consumption of opioids was 16.5 defined daily doses (DDD)/1000 inhabitants (inh)/day, whereas in 2015 the consumption was 15.6 DDD/1000 inh/day; in 2017 it had further decreased (14.9 DDD/1000 inh/day $)^{30}$.

It is noteworthy that our study probably describes the physicians' prescription patterns even more than their patients' opioid need or use. The controls from the GP as well as patients before IA diagnosis usually receive their drug prescriptions from primary care physicians, whereas patients who receive IA diagnosis and are started on DMARD are usually monitored in rheumatologic clinics at least the first 2 years after diagnosis and also get their drug prescriptions from there. Our study showed the drop in opioid use after diagnosis when patients were presumably monitored by rheumatologists, but the numbers did not reach population levels during the 1-year followup. In a US study, almost $50 \%$ of patients with RA who used opioids had received their opioid prescriptions from a rheumatologist ${ }^{25}$.

The main strength of our study is its nationwide scope and the availability of high-quality public registries. The study includes basically all Finnish patients with early IA who are started on DMARD. The patient identification is based on diagnoses (ICD-10 codes) formulated by qualified specialists or special clinics. In Finland, opioids are available only by prescription, and are thus inclusively covered in the register we used. Also, inclusion of population controls strengthens the study and allows estimation of opioid use for arthritis pain, although we lack detailed indications of analgesics therapy.

The limitations of our study include the lack of clinical and health behavior data. Moreover, we have no data on the activity of IA or patient-level pain scores. Further, both NSAID and paracetamol can also be purchased over the counter, and those purchases are not covered in the Drug Purchase Register. However, although our report underestimates NSAID and paracetamol consumption, it is likely to be equal for both patient and control groups, and thus does not cause a substantial bias. We were not able to record the drugs used during possible hospital stays, but in Finland IA treatment is basically outpatient-based so this should not cause too large a bias. Finally, we do not know confidently whether the patients or GP used their purchased medications as prescribed.

Among newly diagnosed patients with IA, the use of opioids for arthritis pain during 2009-2015 in Finland was less common compared to reports from some Western countries, and it is concentrated on mild opioids. The use of opioids seems to decrease when patients receive the IA diagnosis and are started on DMARD, especially among seropositive patients with RA.

\section{ACKNOWLEDGMENT}

The authors thank professor emerita Liisa Rantalaiho for her help with the English language of this manuscript.

\section{REFERENCES}

1. Whittle SL, Richards BL, Buchbinder R. Opioid analgesics for rheumatoid arthritis pain. JAMA 2013;309:485-6.

2. McWilliams DF, Walsh DA. Factors predicting pain and early discontinuation of tumour necrosis factor-alpha-inhibitors in people with rheumatoid arthritis: results from the British Society for Rheumatology Biologics Register. BMC Musculoskelet Disord 2016;17:337.

3. Lee YC, Nassikas NJ, Clauw DJ. The role of the central nervous system in the generation and maintenance of chronic pain in rheumatoid arthritis, osteoarthritis and fibromyalgia. Arthritis Res Ther 2011;13:211.

4. Borenstein DG, Hassett AL, Pisetsky D. Pain management in rheumatology research, training, and practice. Clin Exp Rheumatol 2017; 35 Suppl 107:2-7.

5. Heiberg T, Kvien TK. Preferences for improved health examined in 1,024 patients with rheumatoid arthritis: pain has highest priority. Arthritis Rheum 2002;47:391-7.

6. Lee YC. Effect and treatment of chronic pain in inflammatory arthritis. Curr Rheumatol Rep 2013;15:300.

7. Whittle SL, Colebatch AN, Buchbinder R, Edwards CJ, Adams K, Englbrecht M, et al. Multinational evidence-based recommendations for pain management by pharmacotherapy in inflammatory arthritis: integrating systematic literature research and expert opinion of a broad panel of rheumatologists in the $3 \mathrm{e}$ initiative. Rheumatology 2012;51:1416-25.

8. Radner H, Ramiro S, Buchbinder R, Landwe RB, van der Heijde D, Aletaha D. Pain management for inflammatory arthritis (rheumatoid arthritis, psoriatic arthritis, ankylosing spondylitis and other spondylarthritis) and gastrointestinal or liver comorbidity. Cochrane Database Syst Rev 2012;1:CD008951.

9. Marks JL, van der Heijde DM, Colebatch AN, Buchbinder R, Edwards CJ. Pain pharmacotherapy in patients with inflammatory arthritis and concurrent cardiovascular or renal disease: a Cochrane systematic review. J Rheumatol Suppl. 2012 Sept;90:81-4.

10. Doherty M, Hawkey C, Goulder M, Gibb I, Hill N, Aspley S, et al. A randomised controlled trial of ibuprofen, paracetamol or a combination tablet of ibuprofen/paracetamol in community-derived people with knee pain. Ann Rheum Dis 2011;70:1534-41.

11. Whittle SL, Richards BL, Husni E, Buchbinder R. Opioid therapy for treating rheumatoid arthritis pain. Cochrane Database Syst Rev 2011;11:CD003113.

12. Whittle SL, Richards BL, van der Heijde DM, Buchbinder R. The efficacy and safety of opioids in inflammatory arthritis: a Cochrane systematic review. J Rheumatol Suppl. 2012 Sept;90:40-6.

13. Chaparro LE, Furlan AD, Deshpande A, Mailis-Gagnon A, Atlas S, Turk DC. Opioids compared with placebo or other treatments for chronic low back pain: an update of the Cochrane Review. Spine 2014;39:556-63.

14. Hayes CJ, Payakachat N, Li C. Evaluation of opioid use among patients with back disorders and arthritis. Qual Life Res 2018;27:3021-35.

15. Wiese AD, Griffin MR, Stein CM, Mitchel EF Jr, Grijalva CG. Opioid analgesics and the risk of serious infections among patients

Personal non-commercial use only. The Journal of Rheumatology Copyright $($ C 2020. All rights reserved. 
with rheumatoid arthritis: a self-controlled case series study. Arthritis Rheumatol 2016;68:323-31.

16. Acurcio FA, Moura CS, Bernatsky S, Bessette L, Rahme E. Opioid use and risk of nonvertebral fractures in adults with rheumatoid arthritis: a nested case-control study using administrative databases. Arthritis Rheumatol 2016;68:83-91.

17. Kern DM, Chang L, Sonawane K, Larmore CJ, Boytsov NN, Quimbo RA, et al. Treatment patterns of newly diagnosed rheumatoid arthritis patients from a commercially insured population. Rheumatol Ther 2018;5:355-69.

18. Hamunen K, Paakkari P, Kalso E. Trends in opioid consumption in the Nordic countries 2002-2006. Eur J Pain 2009;13:954-62.

19. Fredheim OM, Skurtveit S, Breivik H, Borchgrevink PC. Increasing use of opioids from 2004 to 2007 - pharmacoepidemiological data from a complete national prescription database in Norway. Eur J Pain 2010;14:289-94.

20. Bosetti C, Santucci C, Radrezza S, Erthal J, Berterame S, Corli O. Trends in the consumption of opioids for the treatment of severe pain in Europe, 1990-2016. Eur J Pain 2019;23:697-707.

21. Coffey C, Crowson CS, Myasoedova E, Matteson EL, Davis JM 3rd. Delay of diagnosis and treatment in seronegative rheumatoid arthritis: missing the window of opportunity [abstract]. Arthritis Rheumatol 2017;69 Suppl 10:1819.

22. Franklin PD, Karbassi JA, Li W, Yang W, Ayers DC. Reduction in narcotic use after primary total knee arthroplasty and association with patient pain relief and satisfaction. J Arthroplasty 2010;6 Suppl:12-6.

23. Zamora-Legoff JA, Achenbach SJ, Crowson CS, Krause ML, Davis JM 3rd, Matteson EL. Opioid use in patients with rheumatoid arthritis 2005-2014: a population-based comparative study. Clin Rheumatol 2016;35:1137-44.
24. Lee YC, Kremer J, Guan H, Greenberg J, Solomon DH. Chronic opioid use in rheumatoid arthritis: prevalence and predictors. Arthritis Rheumatol 2019;71:670-7.

25. Curtis JR, Xie F, Smith C, Saag KG, Chen L, Beukelman T, et al. Changing trends in opioid use among patients with rheumatoid arthritis in the United States. Arthritis Rheumatol 2017;69:1733-40.

26. Jobski K, Luque Ramos A, Albrecht K, Hoffmann F. Pain, depressive symptoms and medication in German patients with rheumatoid arthritis-results from the linking patient-reported outcomes with claims data for health services research in rheumatology (PROCLAIR) study. Pharmacoepidemiol Drug Saf 2017;26:766-74.

27. Sloan VS, Sheahan A, Stark JL, Suruki RY. Opioid use in patients with ankylosing spondylitis is common in the United States: outcomes of a retrospective cohort study. J Rheumatol 2019;46:1450-7.

28. Hooten WM, St Sauver JL, McGree ME, Jacobson DJ, Warner DO. Incidence and risk factors for progression from short-term to episodic or long-term opioid prescribing: a population-based study. Mayo Clin Proc 2015;90:850-6.

29. Chen TC, Chen LC, Kerry M, Knaggs RD. Prescription opioids: regional variation and socioeconomic status - evidence from primary care in England. Int J Drug Policy 2019;64:87-94.

30. Finnish Medicine Agency (FIMEA). Consumption. Drug consumption statistics. [Internet. Accessed February 27, 2020.] Available from: www.fimea.fi/web/en/databases_and_registeries/ consumption 